\title{
Motivation for Learning: An Implicit Decision-Making Process
}

\author{
David Palmer \\ School of Education, University of Newcastle, Newcastle, Australia \\ Email: David.Palmer@newcastle.edu.au
}

How to cite this paper: Palmer, D. (2016) Motivation for Learning: An Implicit Decision-Making Process. Creative Education, 7, 2380-2388.

http://dx.doi.org/10.4236/ce.2016.716229

Received: September 8, 2016

Accepted: October 11, 2016

Published: October 14, 2016

Copyright $\odot 2016$ by author and Scientific Research Publishing Inc. This work is licensed under the Creative Commons Attribution International License (CC BY 4.0).

http://creativecommons.org/licenses/by/4.0/

(c) (i) Open Access

\begin{abstract}
Motivation for learning is concerned with the activation of learning behaviors. It has previously been proposed that decision-making models might offer an explanation for how learning behaviors do become activated. The aim of this position paper was to investigate this proposal. The three main decision-making models were described and analyzed. There were problematic aspects common to all the models, so it was argued that some modifications were necessary, in the following way. It was proposed that there are many factors that can influence learning behaviors, and some of these would have a positive influence (e.g., high self-efficacy, high individual interest, supportive peers) whereas others would have a negative influence (e.g., very low selfefficacy, lack of individual interest, disruptive peers, hunger and fatigue). In one particular lesson, a student could experience a combination of positive and negative factors, so this implies that a decision-making event would be necessary in order to determine whether or not learning behaviors become activated. For several reasons, it was concluded that at least part of the process of comparing the factors and making a decision could occur at a subconscious level.
\end{abstract}

\section{Keywords}

Motivation, Self-Efficacy, Individual Interest

\section{Introduction}

Motivation is the term used to describe the mechanisms that activate and direct behavior. However, although there has been a large amount of research on educational motivation, it is not yet clear exactly how learning behaviors do become activated or directed. Wentzel and Wigfield (2009) for example, noted that in recent years many authors had depicted motivation as "a complex interplay of individual processes and contextualized experiences" (p. 6), but they argued that student motivation was still far 
from being fully understood. In trying to identify a way forward, Maehr and Zusho (2009) suggested that motivation should be considered as a process in which several factors collectively contribute and figure strongly in the outcome. They proposed that achievement goals, for example, should be considered as part of a larger and more situated process involving a combination of critical variables. In their view, reviving a choice and decision theory model might help to clarify the nature of motivation and its causes. The aim of the present paper is to follow up on this idea, by determining to extent to which decision-making models can offer a plausible mechanism for the activation of learning behavior.

\section{Decision-Making Models of Motivation}

Decision theories focus on how people choose between different goals or different actions. Mook (1996) argued that any action requires a cognitive decision, so we "imagine each possible action, consider its consequences, and perform the action whose expected or imagined consequences we most prefer" (p. 365). This view arose primarily from the work of John Atkinson, Julius Kuhl, Heinz Heckhausen, and their colleagues. The contributions of these authors are briefly summarized as follows.

\subsection{John Atkinson}

Atkinson (1966) aimed to account for an individual's selection of one path of action from amongst a set of possible alternatives. He proposed that for each act there would be a motive comprising an approach tendency and an avoidance tendency: The approach tendency would result from the perceived opportunity to maximize satisfaction and achieve success, whereas the avoidance tendency would result from perceived negative consequences, such as potential experiences of pain or failure. He proposed that for each potential act there would be a summation of approach and avoidance motives, as well as a consideration of the expectancy of goal attainment and the incentive value of the accomplishment. The act chosen from amongst a set of alternatives would be the one for which the resultant computation of Motive $\times$ Expectancy $\times$ Value is most positive.

\subsection{Julius Kuhl}

According to Kuhl (1984), a person would have several action alternatives available from which to choose. He argued that one action would have the highest Expectancy $x$ Value product, but it would not necessarily be the action chosen, as people often commit themselves to non-dominant courses of action if they are obliged to do so. Thus, the admission rules would include consideration of the extent to which obligations should be given priority over wishes, as well as the extent to which each offered the greatest product of expectancy and value. In this way, a person could suppress hedonistic urges in order to accomplish a task which might not be as desirable. This decisionmaking process would result in the formation of an intention, which would be stored in working memory until it is executed. During the intervening period, a process of voli- 
tional control would be necessary to shield the intention from competing tendencies, and to ensure that it would not be replaced by a competing tendency. Finally, performance control measures would come into play after the selected action has been initiated. For example, if it becomes clear that an aspired goal has been reached, or it cannot be reached, then this information would feed back into the system, resulting in an exit from the current cycle.

\subsection{Heinz Heckhausen}

Heckhausen and Gollwitzer (1987) proposed that, when choosing between alternative goals and their implied courses of action, two distinct psychological states were involved. The predecisional state was labeled as motivation, which was viewed as a conscious process involving deliberation on the incentives and probabilities of attainment of different goals. This process would involve anticipating what would happen should one choose an action, assessing future realities, and weighing the possibilities for acting, in order to reach a resolution. This state of mind would end with the conscious event of making a decision. The postdecisional state was labeled as volition and this would involve "consideration of when and how to act for the purpose of implementing the intended course of action" (p. 103). The authors used the metaphor of Julius Caesar crossing the Rubicon to describe the transition from the motivational state of deliberation to the volitional state of implementation, and the different kind of cognitive functioning required.

\subsection{Analysis of These Models}

The models were similar in that they all involved the conscious selection of one path of action from amongst a set of possible alternatives. In other words, they were largely concerned with how the direction of behavior is determined. The three models indicated that decision-making would involve consideration of expectancies and values (it should be noted that Expectancy $\times$ Value theories were especially influential when these models were conceived; Heckhausen \& Gollwitzer, 1987 as well as some other factors such as approach/avoidance motives (Atkinson, 1966) and obligations (Kuhl, 1984). The decision-making process was proposed to result in either a choice of action (Atkinson, 1966), or an intention and volitional strategies (Kuhl, 1984), or a goal and volitional strategies (Heckhausen \& Gollwitzer, 1987). In support of these models, there are many real-life situations in which a conscious decision is made to pursue a particular course of action (see Mook, 1996).

However, there are two problematic aspects when these models are applied to classroom learning situations. The first is that the model simply that widely different types of classroom behaviors, such as learning, doodling, daydreaming, conversing with peers, or being disruptive, can be considered as a set of alternative options. This assumes that different types of human behaviors are governed by a single mechanism, but this has not yet been established. Indeed, the causes of many human behaviors are believed to be complex and are still debated (e.g., Burt, Klahr, Rueter, McGue, \& Iacono, 
2011). Consequently, the mechanisms determining the direction of student behavior in classrooms cannot be reliably identified until we understand the causes of each of those behaviors. Thus, it would be premature to assume that widely different types of classroom behaviors simply represent a set of alternative options. As a result, the focus of this paper will be only on motivation for learning and the behaviors of learning. This does not mean that decision theory should be discarded though, as it will be argued that a yes/no decision still needs to be made for whether or not a learning behavior will become activated at a particular time and place.

The second problematic aspect is that the models all imply that one behavior causes another, so they do not identify the mechanism that instigated the initial behavior. As this paper has a focus on learning, the example of learning behavior will be used to illustrate this problem. There are two types of learning behaviors: Overt behaviors are those that are physically observable, including actions such as looking at the teacher, answering a question or writing a summary; but learning is primarily a cognitive activity, so cognitive operations such as focusing attention, thinking, recalling, comparing, analyzing, and reflecting are actions in their own right (Mook, 1996) and these have been referred to as cognitive learning behaviors (e.g., Furinghetti \& Morselli, 2009). Similarly, cognitive decision-making is a conscious action requiring effort, so it is a cognitive behavior. Thus, when one consciously compares the advantages and disadvantages of a particular action or goal, one is engaged in a behavior. In this way, the models imply that the behavior of decision-making would cause the behavior of learning. They have not explained the phenomenon that activated the original behavior of decisionmaking. Again, this does not mean that decision theory should be discarded. These models proposed that decision-making is cognitive and therefore conscious. It will be argued in this paper though, that a subconscious process of decision-making is the mechanism initially responsible for activating learning behavior.

In summary, the earlier models portrayed the direction of behavior as being determined by conscious decision-making. However, when applying this idea to learning situations, it is not yet clear whether all types of classroom behaviors are governed by the same mechanism, so the idea of choosing between a set of alternatives is problematic. In addition, the models have not explained the activation of cognitive behaviors. In the following section, it will be argued that a modified decision-making process can address both of these problems.

\section{An Implicit Decision-Making Process}

In the previous section, it was found that the decision-making models were problematic when applied to classroom learning situations, as it would be premature to propose how the direction of student behavior is determined. For this reason, the remainder of this paper will focus only on the activation of learning behaviors. It will be proposed that, with some modifications, a decision-making process can still plausibly explain this phenomenon. 


\subsection{Factors That Affect Learning Behaviors}

The models described in Section 1 proposed that decision-making would involve consideration of factors such as expectancies, values, and obligations. In more recent years, a much wider range of factors has been identified, and it is now well-established that learning behaviors can be influenced by a number of internal (i.e., personal) factors, with notable examples including self-efficacy (Bandura, 1997), expectancies and values (Wigfield \& Eccles, 1994), attributional beliefs (Weiner, 1986), individual interest (Hidi, 1990), achievement goals (Ames, 1992), and psychological needs (Niemiec \& Ryan, 2009). However, although all of these factors can influence learning behaviors, they do not directly determine whether learning behaviors become activated. Schunk (2000) noted that factors such as self-efficacy and goals do not always predict behavior, and that there can be occasions on which other factors such as fatigue and hunger can preclude all learning behaviors (Schunk, 2004). Thus, even the combined effects of achievement goals, values, and beliefs do not always determine behavior, as a student might have a set of fully positive goals and beliefs for learning in history, for example, but there might still be a history lesson in which that student is too hungry or too tired to concentrate. This implies that, on occasion, other factors can interfere to prevent one's long-term beliefs, achievement goals, values, and interests from having an effect, so they are not direct determinants of behavior. Instead, they are better viewed as factors that can influence behavior.

Similarly, the process of self-regulation can result in the formation of plans, goals, and intentions to perform learning behaviors (Pintrich, 2004), but these are not direct determinants of behavior, as contextual factors can impede or interfere with individual efforts at self-regulation. For example, Boekaerts and Cascallar (2006) argued that some students have a self-regulation system that works well in some content domains but not in other domains, in which it can break down under the effect of particular learning conditions. Thus, the plans, goals, and intentions that are created by self-regulation are better regarded as factors that can influence learning behavior, rather than direct determinants of learning behavior.

The research has also identified a number of other factors, external to the individual, that can influence learning behaviors, and these include teacher enthusiasm (Brigham, Scruggs, \& Mastropieri, 1992), real world relevance (Zusho, Pintrich, \& Coppola, 2003), peers (Nelson \& DeBacker, 2008), extrinsic rewards (Niemiec \& Ryan, 2009) and the presence of novelty (Hidi, 1990). Thus, there is a range of internal and external factors that are known to influence learning behavior.

\subsection{Rationale for a Decision-Making Process}

Although there are many factors that can influence learning behaviors, their effects can differ markedly. Some will have a positive influence in that they will tend to support the activation of learning behaviors, whereas others will have a negative influence in that they will work against the activation of learning behaviors. Positive factors might include high self-efficacy, mastery goals, or high individual interest, as well as favorable 
external factors such as supportive peers and good teaching. Negative factors might include low self-efficacy, lack of individual interest, boring pedagogy, the presence of peers who do not value learning, and physical factors such as discomfort, hunger, and fatigue.

The existence of positive and negative factors implies that a decision-making event is necessary. In one particular lesson, a student might experience a mixture of positive and negative influences: This student might enter a history lesson for example, with high self-efficacy and a mastery goal for learning history, but may be forced to sit with peers who are disruptive, while listening to a boring, teacher-directed presentation. In this type of situation, it is difficult to predict whether or not learning behaviors will become activated. It would be sensible to assume however, that the positive and negative factors would need to be compared in order to decide the outcome. This implies that a comparison of positive and negative factors is necessary, followed by a decision to either activate or not activate learning behaviors.

This process of comparison and decision-making would be the thing that directly determines whether or not learning behaviors will become activated in a particular time and place. In this way, motivation can be viewed as a decision-making process. This process would differ from previous decision-making models because it would not involve selection of one behavior over another, but rather it would simply be a yes/no decision of whether or not to activate learning behavior. Put simply, when positive factors outweigh negative, then learning behaviors would be activated, but when negative factors outweigh positive then there would be no activation of learning behavior.

\subsection{Characteristics of the Decision-Making Process}

One characteristic of this process is that it must be continuously occurring throughout the day. People are able to learn at any time of the day, as they become exposed to new or unexpected learning opportunities (e.g., Braund \& Reiss, 2006). This implies that there must be a continuous process of scanning the external environment in order to immediately identify learning opportunities whenever they may be perceived. One's internal environment would also need to be monitored at the same time, in order to decide whether the physical needs, psychological needs, individual interests, values, beliefs, and intentions were, on balance, supportive of learning at that time and place. Previous decision-making theory has also recognized the need for a continuous stream of incoming information on which to base decisions (Kuhl, 1984), and this is consistent with evidence that throughout human evolution, successful goal-directed behavior would involve individuals scanning for information in both the external and internal environments (Hills, 2006). This information would become factored into the continuous process of decision-making, so that when positive factors predominate then learning behaviors would be activated.

A second characteristic is that the process of decision-making must be subconscious, for the following reasons. Firstly, the decision-making process has been argued to be continuously occurring, even when learning behaviors are not being activated. Anec- 
dotally though, most people do not consciously spend their waking hours comparing the positive and negative factors in the internal and external environments. In other words, people are not usually aware that such a decision-making process is happening, which suggests that it might be subconscious. Secondly, there can be occasions on which multiple cognitive procedures can occur almost simultaneously (Pintrich, 2004) and in such situations it is difficult to see how there could be enough time for conscious comparison, reflection, or decision-making. For example, the focusing of attention is a learning behavior, and it has been found that surprising or unexpected experiences can cause students to spontaneously focus attention on the event and try to learn from it (Hidi, 1990; Mancuso, 2010). Thirdly, recent studies have provided evidence that achievement behaviors can be influenced by subconscious reactions to such things as evaluative grade letters (Ciani \& Sheldon, 2010) and even the presence of color (Elliott, Maier, Moller, Friedman, \& Meinhart, 2007). This suggests that the processing of relevant stimuli can be occurring below the level of consciousness. Finally, in neurological research, it is well-established that subconscious decision-making precedes conscious action (Fried, Mukamel, \& Kreiman, 2011). For example, Yordanova et al. (2011) found that goal-directed behavior, such as focusing attention on a task, is controlled by cortical activation patterns that occur below the level of awareness, and precede the behavior. Thus, there are good reasons to believe that subconscious decision-making may be involved in the activation of learning behavior.

In summary, the process of motivation for learning would involve continuous monitoring of the external and internal factors that can influence learning behavior. Along with this, there would be a subconscious, or implicit, process of comparison and decision-making that is continually updated as new information arrives. Sometimes this process would result in the activation of learning behavior, but at other times it would not, depending on the various combinations of positive and negative factors currently operating.

\section{Conclusion and Implications}

It has been argued in this paper that although the earlier, decision-making models of motivation are problematic in terms of explaining learning behavior, the idea of a decision-making process is still worth considering. By making some modifications to the earlier models, it has been proposed that a process of implicit decision-making could be responsible for the activation of learning behaviors.

In summary, motivation would firstly involve continuous monitoring of the internal and external factors that can influence learning behaviors. Along with this, there would be a subconscious process of comparison and decision-making that is continually updated as new information arrives. If negative factors outweigh positive then task engagement would not occur, but the process of comparison and decision-making would continue in order to identify any future learning opportunities.

Finally, the implication for teachers is that students will be more likely to use deep learning behaviors when positive external factors such as teacher enthusiasm, novelty 
and relevance are provided, and strategies to enhance positive internal factors such as self-efficacy beliefs, expectancies, values, attributions, individual interests and selfregulatory intentions are well-established in the classroom.

\section{References}

Ames, C. (1992). Classrooms: Goals, Structures, and Student Motivation. Journal of Educational Psychology, 84, 261-271. http://dx.doi.org/10.1037/0022-0663.84.3.261

Atkinson, J. W. (1966). Motivational Determinants of Risk-Taking Behavior. In J. W. Atkinson, $\&$ N. T. Feather (Eds.), A Theory of Achievement Motivation (pp. 11-29). New York, NY: John Wiley \& Son.

Bandura, A. (1997). Self-Efficacy: The Exercise of Control. New York, NY: W.H. Freeman and Co.

Boekaerts, M., \& Cascallar, E. (2006). How Far Have We Moved toward the Integration of Theory and Practice in self-regulation? Educational Psychology Review, 18, 199-210.

Braund, M., \& Reiss, M. (2006). Towards a More Authentic Science Curriculum: The Contribution of Out-of-School Learning. International Journal of Science Education, 28, 1373-1388. http://dx.doi.org/10.1080/09500690500498419

Brigham, F. J., Scruggs, T. E., \& Mastropieri, M. A. (1992). Teacher Enthusiasm in Learning Disabilities Classrooms: Effects on Learning and Behavior. Learning Disabilities Research and Practice, 7, 68-73.

Burt, A. S., Klahr, A. M., Rueter, M. A., McGue, M., \& Iacono, W. G. (2011). Confirming the Etiology of Adolescent Acting-out Behaviors: An Examination of Observer-Ratings in a Sample of Adoptive and Biological Siblings. Journal of Child Psychology and Psychiatry, 52, 519-526. http://dx.doi.org/10.1111/j.1469-7610.2010.02334.x

Ciani, K. D., \& Sheldon, K. M. (2010). A versus F: The Effects of Implicit Letter Priming on Cognitive Performance. British Journal of Educational Psychology, 80, 99-119. http://dx.doi.org/10.1348/000709909X466479

Elliott, A. J., Maier, M. A., Moller, A. C., Friedman, R., \& Meinhardt, J. (2007). Color and Psychological Functioning: The Effect of Red on Performance Attainment. Journal of Experimental Psychology: General, 136, 154-168. http://dx.doi.org/10.1037/0096-3445.136.1.154

Fried, I., Mukamel, R., \& Kreiman, G. (2011). Internally Generated Preactivation of Single Neurons in Human Medial Frontal Cortex Predicts Volition. Neuron, 69, 548-562.

http://dx.doi.org/10.1016/j.neuron.2010.11.045

Furinghetti, F., \& Morselli, F. (2009). Every Unsuccessful Problem Solver Is Unsuccessful in His or Her Own Way: Affective and cognitive factors in proving. Educational Studies in Mathematics, 70, 71-90. http://dx.doi.org/10.1007/s10649-008-9134-4

Heckhausen, H., \& Gollwitzer, P. M. (1987). Thought contents and cognitive functioning in motivational versus Volitional States of Mind. Motivation and Emotion, 2, 101-120. http://dx.doi.org/10.1007/BF00992338

Hidi, S. (1990). Interest and Its Contribution as a Mental Resource for Learning. Review of Educational Research, 60, 549-571. http://dx.doi.org/10.3102/00346543060004549

Hills, T. T. (2006). Animal Foraging and the Evolution of Goal-Directed Cognition. Cognitive Science, 30, 3-41. http://dx.doi.org/10.1207/s15516709cog0000 50

Kuhl, J. (1984). Volitional Aspects of Achievement Motivation and Learned Helplessness: Toward a Comprehensive Theory of Action Control. In B. A. Maher (Ed.), Progress in Experimental Personality Research (Vol. 13, pp. 99-171). New York: Academic Press. 
Maehr, M. L., \& Zusho, A. (2009). Achievement Goal Theory: The Past, Present, and Future. In K. Wentzel, \& A. Wigfield (Eds.), Handbook of Motivation in School (pp. 77-104). New York: Routledge.

Mancuso, V. J. (2010). Using Discrepant Events in Science Demonstrations to Promote Student Engagement in Scientific Investigations: An Action Research Study. Doctoral Dissertation, Retrieved from ProQuest Dissertations and Theses, ERIC. (ED521258)

Mook, D. G. (1996). Motivation: The Organization of Action. New York: W.W. Norton \& Company.

Nelson, R. M., \& DeBacker, T. K. (2008). Achievement Motivation in Adolescents: The Role of Peer Climate and Best Friends. The Journal of Experimental Education, 76, 170-188. http://dx.doi.org/10.3200/JEXE.76.2.170-190

Niemiec, C. P., \& Ryan, R. M. (2009). Autonomy, Competence, and Relatedness in the Classroom: Applying Self-Determination Theory to Educational Practice. Theory and Research in Education, 7, 133-144. http://dx.doi.org/10.1177/1477878509104318

Pintrich, P. R. (2004). A Conceptual Framework for Assessing Motivation and Self-Regulated Learning in College Students. Educational Psychology Review, 16, 385-407. http://dx.doi.org/10.1007/s10648-004-0006-x

Schunk, D. H. (2000). Coming to Terms with Motivation Constructs. Contemporary Educational Psychology, 25, 116-119. http://dx.doi.org/10.1006/ceps.1999.1018

Schunk, D. H. (2004). Learning Theories: An Educational Perspective. Upper Saddle River, NJ: Pearson Prentice Hall.

Weiner, B. (1986). An Attributional Theory of Motivation and Emotion. New York: SpringerVerlag. http://dx.doi.org/10.1007/978-1-4612-4948-1

Wentzel, K. R., \& Wigfield, A. (2009). Introduction. In K. R. Wentzel, \& A. Wigfield (Eds.), Handbook of Motivation in School (pp. 1-8). New York: Routledge.

Wigfield, A., \& Eccles, J. S. (1994). Children's Competence Beliefs, Achievement Values, and General Self-Esteem: Change across Elementary and Middle School. Journal of Early Adolescence, 14, 107-138. http://dx.doi.org/10.1177/027243169401400203

Yordanova, J., Albrecht, B., Uebel, H., Kirov, R., Banaschewski, T., Rothenberger, A., \& Kolev, V. (2011). Independent Oscillatory Patterns Determine Performance Fluctuations in Children with Attention Deficit/Hyperactivity Disorder. Brain, 134, 1740-1750. http://dx.doi.org/10.1093/brain/awr107

Zusho, A., Pintrich, P. R., \& Coppola, B. (2003). Skill and Will: The Role of Motivation and Cognition in the Learning of College Chemistry. International Journal of Science Education, 25, 1081-1094. http://dx.doi.org/10.1080/0950069032000052207 
Submit or recommend next manuscript to SCIRP and we will provide best service for you:

Accepting pre-submission inquiries through Email, Facebook, LinkedIn, Twitter, etc. A wide selection of journals (inclusive of 9 subjects, more than 200 journals)

Providing 24-hour high-quality service

User-friendly online submission system

Fair and swift peer-review system

Efficient typesetting and proofreading procedure

Display of the result of downloads and visits, as well as the number of cited articles

Maximum dissemination of your research work

Submit your manuscript at: http://papersubmission.scirp.org/

Or contact ce@scirp.org 